\title{
LER e planos de demissão voluntária: trajetórias de dor e sofrimento entre bancários ${ }^{1}$
}

\author{
Débora Couto de Melo Carrijo ${ }^{\mathrm{I}}$ Vera Lucia Navarro ${ }^{\mathrm{II}}$ \\ ${ }^{\mathrm{I}}$ Centro Universitário de Araraquara

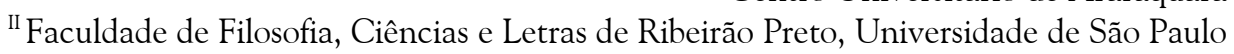

\begin{abstract}
O artigo apresenta resultados obtidos em pesquisa realizada em 2002 com funcionários de um banco estatal de Ribeirão Preto, SP, que foram acometidos por Lesões por Esforços Repetitivos (LER). O objetivo da pesquisa foi conhecer o que determinou o adoecimento e quais foram as repercussões das LER no trabalho e na vida daqueles trabalhadores. Foram entrevistados 10 bancários (6 mulheres e 4 homens) com idades entre 41 e 49 anos. A seleção dos participantes levou em conta dois critérios: a) ser bancário com diagnóstico clínico compatível com LER desenvolvida no exercício da profissão, afastados ou não de suas atividades por este motivo; b) estar ou continuar trabalhando no banco quando da realização da pesquisa. Para todos os entrevistados, a LER significou um marco em sua trajetória de vida e trabalho: ficou evidente que não apenas as atividades profissionais ficaram comprometidas, mas também várias outras de seu cotidiano fora do espaço de trabalho como, por exemplo, atividades domésticas, de cuidados pessoais, de descanso, de lazer. Se as novas tecnologias adotadas pelos bancos, por um lado, otimizaram o trabalho bancário e aumentaram a produtividade, a eficiência dos serviços prestados, a lucratividade do setor, por outro, provocaram aumento da intensidade do trabalho, o que alterou as condições de trabalho e repercutiu na saúde dos bancários. De acordo com os dados obtidos foi possível perceber como os Planos de Demissão Voluntária (PDV) foram utilizados como instrumentos de pressão sobre os trabalhadores. Todos os bancários entrevistados que realizaram o registro da CAT mudaram de função após o diagnóstico de LER.
\end{abstract}

Palavras-chave: Reestruturação produtiva, Saúde do trabalhador, Trabalho bancário.

RSI and voluntary dismissal planes: trajectories of pain and suffering among bank employees

The article presents the results obtained from a study conducted in 2002 with employees of a state-owned bank at Ribeirão Preto, SP, who were affected by Repetitive Strain Injuries (RSI). The investigation aimed at learning about what determined the onset of the disease and the effects of RSI on those employees' lives and work. 10 bank employees (6 females and 4 males) at ages 41 to 49 were interviewed. The selection of participants considered two criteria: a) being a bank employee with a clinical diagnosis which was compatible with RSI developed during professional practice and who had or had not taken a sick leave from work for that reason; b) being at or continuing working for the bank when the study was carried out. To all respondents, RSI meant a mark in their trajectories of life and work. It was evident that not only their professional activities were compromised, but so were various others in their daily lives and out of the work environment, such as household, personal-care, free-time, leisure activities. The new technologies adopted by banks, if on one hand optimized bank work and increased productivity, the efficiency of the services rendered and the profit of the industry, on the other, altered work conditions and affected bank employees' health. According to the data obtained, it was possible to perceive how the Voluntary Dismissal Plans were used as a instrument of pressure against workers. All the bank employees interviewed who issued a official work accident communication changed their positions at work after the RSI diagnosis.

Keywords: Production downsizing, Workers' health, Bank work.

1 Este artigo é originário da dissertação de mestrado da primeira autora, defendida, no ano de 2003, no Programa de Pós-graduação em Saúde na Comunidade da Faculdade de Medicina de Ribeirão Preto da Universidade de São Paulo e orientada pela segunda autora. 
Na realidade, eu pensava em sarar! Ninguém nunca falou que eu não ia sarar. Depois, quando eu vi que eles me deram uma indenização (...), eu falei: o negócio é mais sério, senão eles não iam me dar um dinheiro assim de graça. Não é uma coisa louca? Uma doença que você sabe que não vai morrer dela, mas sabe que vai sofrer... vai ter que enfrentar muita coisa (Entrevistada 9).

\section{Introdução}

$\mathrm{O}$

setor financeiro brasileiro foi pioneiro em adotar a automação e informatizar-se, o que gerou profundas mudanças no processo de trabalho bancário. As novas tecnologias, a intensificação do ritmo de trabalho, a diversificação das tarefas, a adoção de novas formas de gestão da força de trabalho, as terceirizações e as privatizações fizeram e fazem parte do processo de reestruturação produtiva do setor, que levou, em última instância, a eliminação de postos de trabalho, sobrecarga de tarefas e maior pressão e controle sobre os trabalhadores, com graves repercussões sobre as condições de trabalho, de vida e de saúde dos bancários - as LER servem de exemplo.

As transformações advindas do processo de reestruturação produtiva, que atingiram o mundo da produção e do trabalho em escala global, alteraram tanto o aparato tecnológico das empresas, com a incorporação de novas tecnologias, técnicas organizacionais e gerenciais, quanto as relações e as condições de trabalho. $O$ padrão taylorista-fordista, que foi hegemônico ao longo do século XX, passou a ser substituído por modelos mais flexíveis, dentre os quais, o chamado "modelo japonês" ou toyotismo, que inaugurou novo paradigma tecnológico organizacional.

Ancorado nas teses de Harvey (1992), Filgueiras (2001) afirmou que, em essência, esse novo paradigma resume-se na palavra flexibilidade, “(...) a busca permanente para libertar os processos produtivos/comerciais/financeiros, sob o comando do capital, de todas as formas de rigidez próprias do fordismo". No que toca ao aspecto tecnológico, esse novo paradigma representa "(...) a substituição da automação rígida (não programável) de base eletromecânica, pela automação flexível (programável através da informação) de base microeletrônica (...)”. Quanto às novas formas de gestão, “(...) o princípio da flexibilidade se apoia no just-in-time, que implica na economia de todos os elementos da produção e eliminação de todos os desperdícios de todas as 'sobras' e de todos os tempos mortos no interior da jornada de trabalho" (Filgueiras, 2001, p. 282).

No Brasil o processo de reestruturação produtiva ocorreu tardiamente em relação aos países capitalistas centrais e mesmo em relação países latino-americanos. Apenas na década de 1980 a reestruturação produtiva passou a ter visibilidade no país e somente a partir dos anos de 1990 sua expansão ocorreu de forma mais generalizada. Cabe destacar que tal processo ocorre de forma heterogênea entre os países, no interior de cada país, entre diferentes setores da economia e também, de forma diferenciada, entre empresas de mesmo setor. No caso do setor bancário brasileiro, o processo foi marcado por diferenças entre bancos privados e estatais, dado que os últimos demoraram um pouco mais para incorporar as mudanças.

Tendo como pano de fundo as mudanças operadas nos bancos a partir do aprofundamento do processo de reestruturação produtiva do setor, este artigo objetiva discutir 
os reflexos dessas mudanças sobre a saúde dos trabalhadores, baseado em pesquisa realizada com bancários acometidos pelas lesões por esforços repetitivos (LER). Discute-se também como os trabalhadores que adoeceram e foram afastados do trabalho passaram a enfrentar uma nova realidade do cotidiano de vida e trabalho, no qual sentimentos de desmotivação, frustração, discriminação e inferiorização tornaram-se presentes.

\section{Aspectos da reestruturação produtiva no setor bancário brasileiro}

Filgueiras (2001) afirma que no Brasil o setor bancário apresenta especificidades determinantes em seu processo de reestruturação produtiva: é um setor extenso e concentrado, oferece grande diversidade de serviços e é um dos que mais se beneficiou com as altas taxas de inflação que atingiram o país por longo período; o autor chamou a atenção para o fato de que, mesmo após a queda da inflação, que ocorreu com a implementação do Plano Real ${ }^{2}$, o setor bancário continuou a beneficiar-se das altas taxas de juros praticadas pelo governo que sustentaram a "(...) 'âncora cambial' que dava estabilidade aos preços. Assim, tanto nos tempos de inflação alta quanto nos de baixa, os bancos ganharam com o financiamento da dívida pública" (Filgueiras, 2001, p. 284).

O setor financeiro brasileiro foi um dos primeiros a adotar e utilizar a automação e a informatização, cuja busca foi pautada pela “(...) disputa no mercado pela busca de maior agilidade nas informações, característica reforçada pelos aprimorados esquemas de indexação que prevaleceram ao longo das últimas décadas" (Cerqueira \& Amorim, 1997, p. 402).

O processo de reestruturação produtiva ocorreu acompanhado do processo de privatização e desnacionalização do setor, o que, de forma geral, provocou mudanças na forma de ser do trabalho bancário que implicaram em redução do número de postos de trabalho, intensificação de seu ritmo, precarização das relações de trabalho, perda da estabilidade no emprego e aumento do contingente feminino na categoria. Observou-se também a redefinição de funções tradicionais, o aumento de contratos regidos pela terceirização e a utilização, em larga escala, de trabalho de estagiários (Blanco, 1994; Filgueiras, 2001; Jinkings, 1999; Ribeiro, 1997; Segnini, 1995). Em suma, tais mudanças produziram alterações no processo de trabalho e nas regras de contratação e de remuneração dos trabalhadores que repercutiram negativamente nas condições de trabalho e na saúde dos bancários.

\section{Reestruturação produtiva nos bancos e o adoecimento dos trabalhadores}

A alta incidência de LER entre os bancários brasileiros observada com o aprofundamento da reestruturação produtiva do setor fez com que essa síndrome passasse a ser conhecida como "doença de bancários". Ribeiro (1999) relatou que em 20 de agosto de 1994 foi realizado um encontro de portadores de LER do Banco do Estado de São Paulo nas dependências da Faculdade de Saúde Pública da Universidade de São Paulo onde compareceram 350 bancários vítimas da LER: "Não temos notícias de outros encontros no país que reunissem tantos adoecidos do trabalho de uma mesma doença, com a particularidade de pertencerem a uma única empresa" (p. 15).

2 O Plano Real, implantado em 1993 pelo Governo Itamar Franco, teve como um de seus objetivos conter a inflação e foi desenvolvido pelo Ministério da Fazenda, então comandado por Fernando Henrique Cardoso. 
As LER tomaram proporções epidêmicas em todo o mundo e tornaram-se a doença do trabalho mais comum, sobrepondo-se aos acidentes típicos de trabalho. Segundo Ribeiro (2002),

Da metade do século XX para cá (...) as LER se universalizaram e se fizeram presentes em quase todas as categorias de trabalhadores, com prevalências variáveis entre 5\% a 30\%. Em termos tecnológicos, o que assinala esta universalidade é a automação micro-eletrônica simbolizada pelo computador".

No entanto, o autor lembra que, como nas outras vezes que foram modificados os aparatos tecnológicos, "(...) as mudanças não ocorreram apenas nas tecnologias de processo, mas nas relações e controle internos do trabalho".

Ribeiro (2002) afirmou que esse tipo de adoecimento está presente entre trabalhadores das mais diversas atividades econômicas.

Acompanhando a "globalização" e a incorporação das novas tecnologias de automação e as novas formas de racionalização da produção e do trabalho, as LER ganharam sucessivamente o Japão, os países industrializados da Europa, a Austrália, os Estados Unidos da América do Norte e mais recentemente os países de industrialização periférica, como o Brasil (Ribeiro, 2002).

Seu reconhecimento como doença ocupacional ocorreu nos EUA, em 1986, e, no Brasil, em 1991, através de Norma Técnica para Perícia Médica do Instituto Nacional do Seguro Social (INSS) (Assunção, 1995, p. 176).

Discutindo os resultados do estudo de Lima (1998) com bancários portadores de LER, Gravina e Rocha (2006) comentam: "foram citados como principais fatores para a gênese da doença: a automação, o horário de trabalho, as condições ambientais, a sobrecarga no trabalho, os critérios de avaliação, a responsabilidade excessiva, as características pessoais e a impossibilidade de realização profissional” (p. 42).

Dessa forma, para conhecer os determinantes das LER e poder combatê-las é necessário conhecer o processo de trabalho e o contexto no qual têm sido operadas suas mudanças. No caso do trabalho bancário, a automação destaca-se como uma das importantes mudanças introduzidas no setor e, com seu advento, alteram-se as exigências do trabalho, que passa a prescindir da "força bruta", característica de ciclos anteriores da produção capitalista. Para Ribeiro (1999), agora, "os esforços são bem mais leves, mas contínuos, rápidos, dando a impressão de serem inócuos (...) a cabeça e os olhos seguem os passos rápidos da produção, as mãos se movimentam mais que o resto do corpo e os braços as acompanham" (p. 92). Tais modificações, ocorridas em meio à intensificação do processo de reestruturação produtiva do setor bancário, contribuíram para o agravamento das condições de trabalho e saúde dos trabalhadores do setor.

Para Sato (2001), o crescimento das LER tem obrigado,

(...) quer pela frequência com que têm sido diagnosticadas, quer pela ausência de preconceitos em relação a categorias profissionais as quais atinge - trabalhadores e empresários, órgãos governamentais das áreas da saúde, do trabalho e da previdência social, universidades, cada um a seu modo, a lidar com esse problema (p. 148). 


\section{As tensões geradas pelas demissões voluntárias}

A coleta de dados desta pesquisa ocorreu no início de 2002, período marcado pela desnacionalização do setor financeiro no país. $O$ tema das privatizações em curso foi recorrente durante as entrevistas. Como o banco era estatal, para o desligamento dos funcionários foram lançados os "Programas de Demissão Voluntária" ou "Programas de Desligamento Voluntário" (PDV).

A partir de meados da década de 1990, houve pressão sobre os funcionários dos bancos estatais para que aderissem aos PDVs. Muitos dos "convidados" a participar de tais programas foram aqueles que adquiriram LER entre o final da década de 1980 e o início da de 1990. Tal situação foi frequentemente denunciada na mídia de circulação entre os trabalhadores, como os boletins, os jornais e as revistas da categoria. Em matéria publicada pela Revista do Sindicato dos Bancários, em 2001, são descritos relatos de como os trabalhadores, em especial aqueles que tinham LER, eram pressionados a aderir ao PDV:

Luzia (nome fictício), 48 anos, 17 de banco, conta que depois da intervenção federal sua vida e a de muitos colegas ficou insuportável. Ela já havia contraído doença relacionada às Lesões por Esforços Repetitivos. Ficou de licença por mais de dois anos. Quando voltou, já com o banco sob intervenção, o dia-a-dia de trabalho no banco estava muito diferente (...) Com a abertura do PDV, ela foi "convidada" a aderir. Não se encaixava no perfil exigido pelos novos donos do banco. "O gerente sabia que eu tinha LER e me 'aconselhou' a aderir ao plano. Disse que era melhor eu sair espontaneamente porque tinha receio de me dar uma má notícia posteriormente". Contrariada, Luzia entrou no PDV (Bento, 2001).

Silva et al. (2007) estudaram um grande banco estatal do Estado de Minas Gerais e identificaram que o primeiro grande programa de adequação de quadros na empresa, que procurava reestruturar os chamados Centros de Processamento de Serviços (CESEC), ocorreu em 1990. Parte dessa reestruturação consistiu em terceirização. Com isso, os funcionários foram realocados nas agências e, como não havia condição de alocação para todos, em 1995 foi anunciado o Programa de Desligamento Voluntário (PDV), que pretendia demitir 16.500 trabalhadores: em um mês, treze mil deles haviam aderido ao programa. No documento entregue aos trabalhadores contendo a planilha de cálculos dos valores que poderiam receber, havia a frase "Aceitar o desligamento pode viabilizar a realização de um sonho. Encare o programa dessa forma” (Silva et al., 2007, p. 2951). É nítida na frase a pressão e o esforço para "vender" a ideia de que a demissão seria bom negócio para o trabalhador.

Os depoimentos dos trabalhadores entrevistados para esta pesquisa demonstram que a situação em Ribeirão Preto, SP, à época da pesquisa, era semelhante àquela acima relatada. Uma das trabalhadoras entrevistadas relata sua sensação diante do processo de privatização do banco em que trabalhava:

Eu sinto como se fosse um tanque de guerra que vem rolando em cima de você. Que você corre o máximo que pode, mas ele tá chegando cada dia mais perto e vem para destruir! A nossa relação [com o banco] era muito boa, a gente se sentia uma família (...). Tinha problemas? Tinha, mas era um outro esquema, você tinha a quem recorrer, você tinha um órgão que te defendia. Agora, não tem nada. Só se visa o lucro! (Entrevistada 4).

O próximo relato demonstra que os entrevistados percebiam com clareza o que Jinkings (1999) referia em relação às desigualdades e contradições do modo capitalista de produção:

O banco é uma loja de vendas, então o interesse do banco é vender produto... E se ele não consegue tem que tirar em forma de tarifa do cliente. Então, a gente [funcionários] aparece como sugador. A gente é o órgão que o banco colocou ali para sugar as pessoas. Não é mais como antes, para prestar um serviço. Então, essa não é uma profissão honrosa não (Entrevistada 4). 
Tal depoimento apresentou, além da percepção da trabalhadora sobre a finalidade do banco, sua insatisfação com a nova estrutura do trabalho bancário, bastante diferente da vivenciada no começo de sua carreira na década de 1970.

O novo perfil exigido dos bancários é o de vendedor de produtos e de executor de novos serviços. Nem todos puderam adequar-se. De acordo com Gravina e Rocha (2006), "Os portadores de LER não receberam treinamento e não tinham conhecimento técnico para realizar as tarefas de vendas" (p. 53).

Com a privatização do banco, à medida que ocorriam as demissões dos antigos funcionários, existiam também novas contratações cujos contratos diferenciavam-se dos antigos especialmente por não oferecerem a estabilidade do funcionalismo público. A contratação de funcionários mais novos, assim como de uma grande massa de estagiários, tornou mais acirrada a concorrência entre os trabalhadores. Trabalhadores terceirizados, jovens trabalhadores e estagiários em expansão no trabalho bancário são um desafio para o movimento sindical. Segundo Blanco (1994), “(...) a questão da terceirização passa pelo sigilo bancário, passa pela questão tributária, passa pela saúde do trabalhador, passa pelas condições de trabalho e passa pela própria legislação (...)" (p. 78).

À época da pesquisa, os entrevistados, que haviam ingressado no banco através de concurso público, recebiam em média dez salários mínimos por mês, enquanto os novos funcionários contratados pelo banco já privatizado recebiam cerca de um quarto desse valor. A maior competitividade entre os trabalhadores diante da nova realidade revelou um ambiente de disputas individuais que dificultava o reconhecimento do conjunto dos trabalhadores como pertencentes à mesma categoria, o que prejudicava sua união em torno de interesses comuns. A diferenciação entre trabalhadores de uma mesma categoria teve a capacidade de minar a solidariedade entre eles e dificultou seu reconhecimento enquanto classe, como apontou Antunes (1999) ao chamar a atenção para o quadro de heterogeneização, diversificação e fragmentação da classe trabalhadora na contemporaneidade, que dificulta o resgate do sentimento de "pertencimento de classe".

(...) o próprio banco tem uma política de "desmonte". Pôs os estagiários contra os funcionários para poder desestabilizar (...) (Entrevistada 4).

(...) Eles [gerentes] pegaram o pessoal [mais velho], e jogaram tudo lá atrás. Deixaram uma meninada lá na frente lidando com o público. Eles fizeram uma pesquisa e disseram que os jovens falaram que o banco X era o banco dos pais deles, do avô. O banco não quer isso. Eles querem que seja da geração jovem. (...) E a gente fica na retaguarda, para fazer o serviço que vem para trás (Entrevistada 9).

No depoimento abaixo, um entrevistado de 49 anos relacionou a possibilidade de não permanecer no banco com a influência da nova "imagem" requerida: a de ser jovem.

Eu penso que eu ainda tenho margem de trabalho, mesmo com esses problemas [refere-se a LER], eu ainda acho que dá para trabalhar muito. Não quero parar não! Só depois de aposentado. Mas eu acho que eu não continuo aqui [referindo-se à data do fim da estabilidade], uma porque eu sou mais velho (Entrevistado 5).

Foi possível perceber que os entrevistados estavam mobilizados pela questão da demissão, buscando encontrar justificativas que os incluíssem ou excluíssem não apenas daquele banco, mas em relação ao mercado de trabalho.

Tivemos o PDV no começo do ano passado. Teve pessoas que saíram porque estavam no limite do estresse. Então, não foi uma coisa organizada, pensada: "isso é melhor para mim!", [mas] "eu quero sair daqui agora, não aguento mais ficar aqui!" (...) Eles [gerentes do banco] fazem tudo para minar a resistência das pessoas, porque vai sair um outro plano de demissão voluntária. 
Você percebe que é um jogo, um jogo psicológico. Não é só uma pressão, é um jogo sujo mesmo (Entrevistada 4).

É inerente ao processo de reestruturação produtiva a descartabilidade de trabalhadores e, em um primeiro momento, são descartados aqueles que foram altamente sucateados ao longo de décadas de trabalho nos bancos, como se pode observar no seguinte depoimento:

Tivemos um gerente que teve uma "ideia genial" [fala em tom de ironia]: ele propôs para a regional uma lista de funcionários para receber um PDV dirigido. Dos dez indicados na lista que ele fez, sete funcionários tinham LER. Ele veio falar que existiu uma avaliação na agência e nessa eu não tinha ido muito bem. Eu disse: "eu não acredito em você!". Como que na última avaliação que teve eu tirei nota nove vírgula nove e hoje, pouco tempo depois, eu sou considerada insatisfatória? Agora, se você falar que me botou na lista porque sou uma lesionada e que eu não sou uma funcionária que você pode manipular conforme a sua vontade, aí eu acredito! (Entrevistada 2).

Por muitas vezes os entrevistados utilizaram o termo "lesionado" para caracterizar os portadores de LER. Ao denominar colegas ou ao autodenominar-se dessa forma, o trabalhador define-se pela doença que o acomete, ou seja, ele passa a carregar consigo o fato de "ser lesionado"; a incorporação é tamanha que o trabalhador não apenas "tem" LER, mas ele "é lesionado", é uma pessoa frágil e fraca por ter adoecido, o que demonstra o quanto tal condição é estigmatizante.

A única coisa que a gente ouviu é que talvez fizessem um PDV diferenciado para lesionado. Mas, você quer saber, é que quando entrou no banco tava no auge da juventude, da saúde. Hoje eu tenho 43 anos e tenho problemas que interferem na minha vida! Hoje eu tenho uma idade que, para o mercado, não é interessante e eu tenho um problema que é significativo e, de certa forma, sujou a minha carteira profissional. Em qualquer canto, hoje, você usa a informática e ninguém vai querer uma pessoa que não pode digitar (Entrevistada 4).

Tal depoimento revelou o sentimento de descartabilidade da trabalhadora que, aos 43 anos, considerava-se velha, com a carteira de trabalho "suja" pelo registro de uma doença do trabalho, a LER.

Com o processo de privatização, outra mudança relatada dizia respeito à diminuição do quadro de funcionários que, aliada ao aumento da clientela e das metas a serem cumpridas, sobrecarregou os bancários que permaneceram em seu trabalho.

Nessa forma de organizar o trabalho, busca-se canalizar a energia dos bancários para o que Aubert Gaulyac (citado por Jinkings, 1999, p. 159) considerou como estratégias mercadológicas das empresas, adotadas para mobilizar energia física, afetiva e psíquica do trabalhador.

Embora estabelecido, através de acordo coletivo da categoria, que os antigos funcionários do sistema estatal do banco não estavam obrigados ao cumprimento das metas, estas eram percebidas pelos trabalhadores como forma de serem avaliados e que, sem cumprilas, poderiam colocar em risco seus empregos, já que a privatização trouxera o fim da estabilidade. É importante ressaltar que o cumprimento de tais metas não está relacionado à atividade principal que o bancário realiza, mas sim à venda de produtos do banco, o que muitas vezes representa uma tarefa inviável de ser conciliada com a tarefa principal, por exemplo, pelo trabalhador não ter contato direto com o cliente.

O gerente também sofre pressão, ele tem que produzir... é uma cadeia (...). "Quantos seguros você fez hoje?", "Vendeu Din-Din?3?", "Tem que vender! Nós temos uma meta de tantos!". O

3 Nome comercial de um título de capitalização vendido pelo banco no qual os entrevistados eram funcionários. 
que a gente pergunta para o gerente é: "Como é que você quer que vende? A gente não tem contato com o cliente! Eu vou vender de que jeito? A gente está lá no fundo! Só se eu for vender para as paredes!". (...) brincando, eles falam: "O que você faz da meia noite às seis"? (Entrevistado 10).

Eles falam: "hoje eu quero cinco Din-Din, cinco seguros"! O pessoal sai batendo cabeça! (Entrevistada 7).

A venda de produtos bancários torna-se uma perseguição, pois as pessoas não estão lá para serem vendedoras e os supostos compradores não estão lá para comprar, transformando-se, assim, de uma forma mascarada, o conteúdo da tarefa.

A estratégia de vender produtos, mesmo quando não é objetivo da clientela a sua compra, evidencia que no sistema capitalista, em especial no setor de serviços, a ordem não é mais atender a necessidade do cliente, mas fazer com que este tenha novas necessidades, impulsionando, desse modo, a venda de produtos.

Trata-se de uma tendência atual do trabalho bancário, já descrita por Jinking (1999, p. 154), quando refere que as mudanças ocorridas com o processo de reestruturação produtiva transformaram os bancários em vendedores de produtos e serviços.

Os relatos abaixo demonstram o quanto o trabalhador é avaliado por suas vendas:

Mesmo nesse trabalho que eu faço [trabalha no pré-atendimento com informações para os clientes], tem dias que tem que vender produtos. Em termos de serviço é aquilo que você tem que fazer, não existe meta de serviço mas aquilo é tua função (...). Todo dia eles dão [produtos para vender], mas é assim, não é que você tenha que fazer mas isso te intimida (...)! (Entrevistada 6).

Poupança, aplicações, seguros, tudo isso é uma forma de vender produtos. Nós somos monitorados. Toda a sua produção, tem todo um controle geral do que você faz e o que você não faz (Entrevistado 5).

Os dois relatos acima apresentam também a ambiguidade entre o que é determinação do acordo coletivo e as exigências do cotidiano do trabalho. Já o depoimento abaixo deixa claro o sentimento em relação à sobrecarga de trabalho:

Para a gente, mudou o serviço (...). Dá impressão que melhorou. Só que vai ter uma massa maior de serviço, mas o tempo é o mesmo, né? Dá impressão que se viesse a máquina, a gente ia ter bastante tempo de lazer, mas não! (Entrevistada 9).

Evidencia-se a relação da tecnologia e sua interface com o desemprego de alguns e a sobrecarga de trabalho para os que permanecem trabalhando. Este tipo de inovação tecnológica fez-se suprimindo postos de trabalho e transferindo para os clientes tarefas antes executadas pelos bancários. Gounet (1999), ao analisar as mudanças no processo produtivo na indústria automobilista, afirmou que o toyotismo exige mais do trabalhador que o fordismo e não cumpre também as promessas feitas aos consumidores (clientes). O toyotismo - apresentado como o modelo que traria o "enriquecimento profissional", o "cliente satisfeito", o "controle de qualidade" - "(...) elimina, aparentemente, o trabalho repetitivo, ultra-simplificado, desmotivante, embrutecedor. (...) Neste sistema a intensificação atinge o auge” (p. 33).

A implementação de novas tecnologias no setor bancário implicou também em mais desemprego, atingindo especialmente aqueles que não eram tão jovens (em relação aos novos contratados), mesmo considerando-se que o conhecimento acumulado pelos entrevistados não os diferenciava dos novos funcionários. Todos deviam aprender a operar as novas máquinas e ensinar aos clientes a operar as de "autoatendimento". Diante do novo quadro de organização da produção e do trabalho bancário, a máquina ocupa papel central. A ela é transferido o saber 
tácito dos trabalhadores. A partir de então, o conhecimento já não é mais do trabalhador, que pode ser descartado (Bianchetti, 1999, p. 138).

Outra tensão observada diz respeito à existência de dois quadros de trabalhadores atuando na mesma instituição: os antigos funcionários, admitidos por concursos públicos, e os novos contratados após a privatização. Aos primeiros fica a sensação que sua força de trabalho é descartável, com fim próximo dado o desemprego emergente ou a aproximação da aposentadoria.

Os bancários entrevistados, apesar de adoecidos em consequência do trabalho, estavam em um momento em que nada era mais relevante do que a manutenção de seus empregos, deixando em segundo plano a defesa de melhores condições de trabalho e de sua saúde.

\section{As mudanças no trabalho decorrentes da LER: um marco na trajetória de vida dos bancários acometidos pela doença}

Sete dos dez entrevistados exerciam a função de caixa quando os sintomas de LER iniciaram-se. Os demais começaram a apresentar os sintomas quando trabalhavam nos centros de processamento de dados (CPD) e nas unidades de compensação, conhecidas como CESER.

O trabalho dos caixas era o "cartão de visita" da instituição financeira e caracterizavase pela entrada de dados através da digitação, o que requeria memorização de instruções, concentração e responsabilidade. Nos CPD, as atividades eram relacionadas à preparação, conferência de documentos e entrada de dados no sistema e, nos CESER, as atividades diziam respeito à compensação dos documentos recebidos. Eram trabalhos altamente repetitivos e realizados com vistas a atender às demandas das agências de uma região (Segnini, 1995). Após 1994, os CPDs e os CESERs deixaram de existir e parte das funções deixou de ser necessária, frente à informatização e às mudanças do mundo financeiro.

Lá eu trabalhava à noite. Foi numa época assim: você tinha que entrar e ficar, não eram seis horas de trabalho, você varava a noite naquilo! Na época que eu entrei no núcleo era assim, de passar na padaria e comprar o pão de manhã. Você entrava às sete [da noite] e às sete horas da manhã você estava indo embora (Entrevistada 7).

Em relação à organização e à forma de realizar o trabalho no CESER e no CPD, os depoimentos tornaram ainda mais evidentes a repetição e a fragmentação dos trabalhos lá realizados. O ritmo era intenso e ditado pelo volume de transações ocorridas nas agências, cujo processamento tinha hora para ser finalizado, o que levava os trabalhadores a realizarem muitas horas-extras.

(...) Lá, a gente soma o dia inteiro, eu adorava. Depois eu fui para conferência, que aí eu comecei a ter mesmo muita dor. Eu fiquei dezesseis anos somando. Aí ele [o braço] já não parava de doer (Entrevistada 9).

O depoimento da trabalhadora revelou como o ritmo de trabalho aumentava à medida que eram introduzidas as mudanças no processo de trabalho, o que levava a manifestações de morbidez, muitas vezes com a instalação de quadros de LER.

Na máquina de escrever, apesar de você colocar força, não dói tanto quanto no computador. $\mathrm{O}$ computador é leve e você bate rápido (Entrevistada 6). 
As mudanças no tipo de atividade e o início da percepção da instalação dos sintomas são contemporâneos: dois dos dez entrevistados relataram que os sintomas de LER iniciaram-se no final da década de 1980 (seis deles entre 1991 e 1993 e dois no ano de 1996). A mudança de função ocorreu para todos os trabalhadores que registraram a Comunicação de Acidentes de Trabalho (CAT), dado que o banco cumpriu a norma em atendimento às exigências do INSS. Aos trabalhadores que registraram a CAT foi proibido registro de horas-extras, o que não quer dizer que eles não as realizavam. Tais mudanças de função e as incapacidades motoras daqueles acometidos pela LER originavam casos de segregação: aqueles com LER passaram a executar tarefas que não existiam ou que eram menos respeitadas, como a organização de filas ou o simples oferecimento de informações, o que fazia com que os remanejados de função percebessem seu novo trabalho como algo de menor valor ou aquém de suas potencialidades. Àqueles que passaram a realizar tarefas de retaguarda, escondidos e sem contato com o público, ficou o sentimento de desvalorização, dado que não mais eram "o cartão de visitas" do banco.

O sofrimento e o sentimento de humilhação, quando do retorno ao trabalho após o período de afastamento ocasionado pela LER, foi também observado por Borsoi, Santos e Acário (2006), que afirmaram que os trabalhadores ao retornarem ao banco passavam a ter que lidar com tarefas consideradas

(...) inferiores àquelas realizadas antes do adoecimento. $\mathrm{O}$ caixa-executivo e o atendente do segmento social do banco deixam seus postos de relativo reconhecimento e visibilidade para exercer atividades incompatíveis com seus conhecimentos técnicos, (...) mais afastado do público e dos colegas (Borsoi et al., 2006).

Dois dos entrevistados desta pesquisa realizavam funções relacionadas à contabilidade. Eram tarefas que exigiam atenção, mas envolviam pouco poder de decisão e sua intensidade dependia mais do fluxo de papéis da agência e menos da tratativa com clientes. Cumpri-las dependia do respeito aos prazos relacionados ao envio de documentos e existia flexibilidade em relação à distribuição das tarefas realizadas ao longo do dia.

Duas outras entrevistadas trabalhavam, à época da realização da pesquisa, no préatendimento ao cliente, cujas atividades são de contato com o público, realizadas por uma única pessoa na agência, que tinha por finalidade controlar o tempo e o fluxo de pessoas na agência; seu trabalho, por vezes, eram maior que o trabalho do caixa.

Três entrevistados realizavam cobranças e acordos com clientes inadimplentes. Tal atividade é relevante para o banco, mas as trabalhadoras tinham a percepção de que partes das metas impostas eram inatingíveis:

Sabe aquele pessoal que deve pra caramba? Eu faço uma renegociação da dívida dele. É muito triste, é só problema (...) ah! E tem que vender! Como que eu vou vender um seguro de vida para um cara que está devendo? O cara não tem dinheiro para comer! (Entrevistado 3).

Dois trabalhadores do sexo masculino eram gerentes juniores de pessoa física. Dentre os entrevistados que foram remanejados de função, esse era o cargo de maior destaque, uma vez que envolvia maior poder de decisão e representava ascensão nas carreiras bancárias.

Destacamos que as mudanças de função dos trabalhadores com sequelas de LER aconteceram sem nenhum apoio técnico: os novos postos dos readaptados foram escolhidos aleatória e empiricamente. 


\section{As perdas geradas pela LER}

A dor aguda, no início do quadro de LER, é importante sinal de alerta. No entanto, a instalação lenta faz com que os sintomas iniciais sejam menosprezados. Só quando as dores são intensas, constantes e denunciam que a lesão já se agravou é que os trabalhadores procuram ajuda (Lin, Teixeira \& Barboza, 1998).

Em [19]93 (...) comecei a reclamar que a máquina estava dura, mas eles falavam que era frescura. Tinha dor, braço pesado, mas uma noite de sono ou um fim de semana me recuperava. Entre quando eu fui ao médico até ele pedir o afastamento da função, que foi quando eu travei, não passou de trinta dias, mas já havia um ano que eu já sentia alguma coisa (Entrevistada 1).

(...) antes eu tinha umas dorezinhas, mas eu não ligava. No começo, se eu parasse de somar tão rápido, dava uma melhorada. Mas chegou uma hora que ele já não parava de doer e eu ia embora e doía do mesmo jeito! Aí eu falei: ué? O negócio está ficando feio [lágrimas]! (Entrevistada 9).

A incapacidade foi tema difícil de ser abordado pelos trabalhadores por ser uma nomenclatura que assusta e consolida os sintomas apresentados. Em diversos depoimentos ficou claro que os trabalhadores com sintomas de LER tinham a percepção de suas dificuldades ou mesmo incapacidade em realizar suas antigas tarefas. No entanto, poucos verbalizavam a palavra incapacidade que, para aqueles trabalhadores, tinha o estigma de "invalidez". Os depoimentos que seguem tratam das limitações que estão presentes nas atividades desenvolvidas tanto no espaço produtivo, quanto no espaço reprodutivo.

É dificuldade, não é incapacidade! Eu consigo comer, mas o ritmo mudou. Minha vida é normal, mas eu tenho uma dificuldade para escrever, para comer. Minha letra parece letra de criança. Minha mão é trêmula (Entrevistado 3).

Já não tenho mais força para segurar uma caneta, [ao segurá-la] ponho muito mais força do que realmente preciso. Quando eu tiro a mão, está marcada... então imprimo uma força que só percebo depois que dói (Entrevistada 6).

(...) Só para escrever é coisa que eu paro dez vezes, meu "m" sai com quatro pernas, duas pernas... (Entrevistada 7).

(...) faço tudo mais devagar do que fazia antes. Não tenho mais aquela velocidade que tinha. Inclusive minha letra piorou bastante (Entrevistada 9).

A gente vê isto [as limitações] quando não consegue mais abrir uma garrafa, quando vai pegar um objeto e ele cai da sua mão... (Entrevistada 1).

Eu perdi a noção da força, então eu quebro muito copo, muitas coisas... eu quebro tampa de garrafa, por que às vezes eu acho que não estou fazendo muita força para torcer, para abrir, mas estou. Às vezes eu estou segurando alguma coisa e deixo cair, eu pego no braço de alguém e a pessoa fala: Aaaaiii!!! Para mim eu estou encostando, mas eu estou apertando muito (Entrevistada 4).

Eu fui renovar a carta, o médico mandou apertar um... [dinamômetro]. [Ele] falou: "força!", eu falei: "mas não tem mais força". Aí eu falei do problema da LER e ele falou: "Não, tudo bem!" (Entrevistado 10).

Olha muda a vida da pessoa! Você tem que fazer adequação, é escova de dente... um monte de coisas (...) se eu tiver que lavar roupa, não vou lavar, se tiver que passar, não vou poder (...), eu não vou dar conta (Entrevistada 7).

Eu fazia muita coisa [em casa, nas horas de folga], arrumava parte elétrica, torneira... lavar carro, essas coisas eu gostava de fazer... tem que parar, não tem jeito mais (Entrevistado 10). 
Através de relatos de bancários com LER, Murofuse e Marziale (2001) evidenciaram as mudanças que afetaram diversos aspectos da vida dos trabalhadores que sofriam com angústias e preocupações decorrentes da piora do quadro clínico, tendo em vista que a limitação física comprometia a autonomia e impedia a execução de atividades rotineiras, de cuidados pessoais e domésticos, transporte e lazer, o que tornava os trabalhadores dependentes de outras pessoas.

Trabalhadores entrevistados por Gravina e Rocha (2006) afirmaram que uma das grandes dificuldades associadas às LER é a presença de dores constantes quando do retorno ao trabalho. Segundo aqueles autores, a dor, nas LER, têm causas múltiplas e, por não ser expressa fisicamente, dificulta a "visibilidade" do adoecimento.

Com as LER, as pessoas têm dificuldades relacionadas ao movimento do corpo, à perda da agilidade, da rapidez, da destreza, da precisão. No entanto, as dificuldades não se limitam à falta de movimento. $\mathrm{O}$ excesso de movimento provocou a lesão, o reparo exige repouso. A dor, que passa a ser crônica, é muitas vezes mais percebida quando o corpo fica parado.

Se você vai ao cinema e fica o tempo todo sentadinha, direitinha, isso é um peso terrivel, então a gente tem dificuldade às vezes até de ficar parada (Entrevistada 1).

\section{Quando a LER torna-se pública}

O período de afastamento do trabalho para tratamento de saúde é também uma forma de reconhecimento social da doença. Todos os entrevistados para esta pesquisa tinham diagnóstico clínico compatível com LER e apenas metade deles foram afastados do trabalho pelo INSS. Um dos entrevistados não registrou a CAT.

A discussão em torno da oficialização do adoecimento frente a chefia, colegas e previdência social não é tarefa fácil e é considerada pelos trabalhadores como um desafio a ser enfrentado.

Chegou numa certa época que eu estava no auge da dor, foi em 1999. Eu saí, fui enfrentar o INSS. Foi a pior coisa que eu fiz na minha vida! Eles indeferiram a minha licença. Aí acabou para mim! Fiquei quarenta e cinco dias esperando pelo INSS me dar a resposta e, quando me deu, indeferiu! Eu paguei uma consulta particular para o mesmo médico que havia me avaliado no INSS, oitenta reais, e, aí, ele viu tudo que não viu pelo INSS! Ele falou, que se eu não cuidasse poderia virar um problema irreversivel! (Entrevistada 6).

Para alguns dos trabalhadores acometidos pela doença, a necessidade da validação oficial dos sintomas passa também pela necessidade de provar que não os está simulando. Uma vez tendo se sujeitado às práticas do INSS, é necessário provar que realmente está doente o que, para o trabalhador, é motivo de constrangimento e humilhação. Ribeiro (1999) afirmou que esse aspecto do problema enfrentado pelos adoecidos por LER é mais um agravante do quadro, já que "quando a doença se faz pública, com o afastamento por determinação médica, um longo caminho introspectivo de sofrimento foi percorrido e já ocorreu o distanciamento afetivo dos companheiros de trabalho, desestruturando suas relações" (p. 150). O trabalhador que consegue validar seu adoecimento e sua incapacidade inicia então um novo período de novas percepções.

O tempo que você está afastada, você passa a viver em função da doença. Pior coisa que tem do afastamento é ir no INSS (Entrevistada 7). 
A questão da "invisibilidade" da LER é abordada por Verthein (2001) quando menciona o trabalho da perícia médica do INSS. Para o autor, na perícia leva-se em conta apenas se há edema, espessamento, atrofia, dificuldades de movimentos, ou seja, são consideradas apenas as sequelas passíveis de observação em exames clínicos e complementares. Tais sintomas "Seriam materiais de leitura da veracidade da doença. Em contrapartida, 'o que não pode ser medido' é invisível, não compreendido, principalmente, porque, para os médicos há uma incoerência entre a fala (sentir) do trabalhador e o que é visível para o médico" (p. 14).

Uma das entrevistadas relatou que receava sair de casa no período em que estava afastada do trabalho, pois, caso encontrasse com algum colega de trabalho, ele poderia pensar que ela já estava curada ou, pior, que nunca havia adoecido.

Sofri muito com aquele negócio que você não pode sair na porta de casa com medo de ser tachada como mentirosa e que está apenas querendo ficar afastada do trabalho (Entrevistada 6).

Além de todo o sofrimento causado pela doença, o trabalhador tem ainda que travar uma luta, seja no ambiente de trabalho ou fora dele, para comprovar que é vítima de adoecimento: “(...) eles têm que lidar com o descrédito (...) não só das pessoas com quem trabalham, sejam seus superiores hierárquicos ou colegas de mesmo nível, como também dos próprios profissionais de saúde que os atendem" (Borsoi et al., 2006).

\section{Considerações finais}

Partimos do pressuposto de que o trabalho é a categoria sociológica com maior força explicativa para demonstrar a relação entre o adoecimento das pessoas e sua atividade laboral. É a compreensão de como o trabalho é organizado, de como dá-se concretamente a sua exploração que nos permite estabelecer relações entre a saúde e o trabalho das pessoas. Assim, ao buscar compreender as implicações das LER na vida do trabalhador bancário, foi de fundamental importância ressaltar como as mudanças no mundo do trabalho, resultantes das transformações tecnológicas e organizacionais alcançadas no final do século XX e, em especial, aquelas que atingiram o setor financeiro, foram determinantes na forma de adoecimento dos trabalhadores desse setor.

Se as novas tecnologias adotadas pelos bancos, por um lado, otimizaram o trabalho bancário e aumentaram a produtividade, a eficiência dos serviços prestados, a lucratividade do setor, por outro, provocaram aumento da intensidade do trabalho, uma vez que a redução dos quadros de funcionários nas agências provocou sobrecarga de trabalho. $\mathrm{O}$ conjunto dessas mudanças alterou as condições de trabalho e repercutiu na saúde dos bancários. A LER é um exemplo clássico dessa situação.

Foi possível perceber como os PDVs foram utilizados como instrumentos de pressão sobre os trabalhadores e, de forma mais desumana, sobre aqueles que eram portadores de diagnóstico de LER.

Todos os bancários entrevistados que realizaram o registro da CAT mudaram de função a fim de que o agente patogênico fosse minimizado. No entanto, a forma aleatória como as novas funções foram escolhidas colocou, na maioria das vezes, o trabalhador em situações ainda mais precárias de trabalho, em atividades de menor prestígio, mais vazias de conteúdo.

Para todos os entrevistados, as LER significaram um marco em sua trajetória de vida e de trabalho. Ficou evidente que não apenas as atividades profissionais ficaram comprometidas, 
mas também aquelas do cotidiano fora do espaço de trabalho, como as atividades domésticas, de cuidados pessoais, de descanso e de lazer.

Apesar de já existir significativa produção científica a respeito das LER entre trabalhadores brasileiros, a realidade aponta para a necessidade de realização de estudos que venham contribuir para elucidar esse fenômeno, dado que é um problema em expansão nos diferentes ramos de atividade e que se caracteriza como um grave problema de saúde pública.

Concordamos com Ribeiro (2002) que afirmou:

(...) ser a favor da utopia da preservação da saúde e da prevenção das doenças dos trabalhadores, fazer para que isto aconteça em um horizonte qualquer, não quer dizer que isto venha a ocorrer sem resistência e menos ainda com o beneplácito patronal, pois contraria interesses concretos do capital e sua voracidade intrínseca. Os avanços que houver neste sentido decorrerão das contradições inerentes a este modo de produção e dos movimentos sociais.

\section{Referências}

Antunes, R. (1999). Os sentidos do trabalho: ensaio sobre a afirmação e a negação do trabalho. São Paulo: Boitempo.

Assunção, A. A. (1995). Lesões por esforços repetitivos. In R. Mendes (Org.), Patologia do trabalho. São Paulo: Atheneu.

Bento, L. (2001). O inimigo mora ao lado: berros, humilhação, falta de educação ao requisitar algo. Aquele antigo hábito de algumas chefias tem nome e pode ser denunciado: chama-se assédio moral. Revista dos Bancários, São Paulo, setembro.

Bianchetti, L. (1999). As novas tecnologias e o devassamento do espaço-tempo do saber tácito dos trabalhadores. In B. W. Aued (Org.), Educação para o (des)emprego: ou quando estar liberto da necessidade do emprego é um tormento (pp. 133-149). São Paulo: Vozes.

Blanco, M. C. (1994). O processo de terceirização nos bancos. In H. S. Martins \& J. R. Ramalho (Orgs.), Terceirização: diversidade e negociação no mundo do trabalho. São Paulo: Hucitec.

Borsoi, I. C. F., Santos, A. O. R. \& Acário, S. H. A. (2006). Trabalhadores amedrontados, envergonhados e (in)válidos: violência e humilhação nas políticas de reabilitação por LER/DORT. Revista de Psicologia Política, 6 (12).

Cerqueira, H. E. \& Amorim, W. A. C. (1997). Evolução e características do emprego no setor bancário. In L. Carleal \& R. Valle (Orgs.), Reestruturação produtiva e mercado de trabalho no Brasil. São Paulo: Hucitec.

Filgueiras, L. (2001). Reestruturação produtiva e emprego bancário. In A. Gomes (Org.), O trabalho no século XXI: considerações para o futuro do trabalho. São Paulo: Anita Garibaldi. Bahia: Sindicato dos Bancários da Bahia.

Gravina, M. E. R. \& Rocha, L. E. (2006) Lesões por esforços repetitivos em bancários: reflexões sobre o retorno ao trabalho. Cadernos de Psicologia Social do Trabalho, 9 (2), 41-55.

Gounet, T. (1999). Fordismo e toyotismo na civilização do automóvel. São Paulo: Boitempo.

Harvey, D. (1992). Condição pós-moderna: uma pesquisa sobre as origens da mudança cultural. São Paulo: Loyola.

Jinkings, N. (1999). Trabalhadores bancários: entre o fetichismo do dinheiro e o culto da excelência. In B. W. Aued (Org.), Educação para o (des)emprego: ou quando estar liberto da necessidade do emprego é um tormento (pp. 151-173). São Paulo: Vozes.

Lima, M. E. A. (1998). A LER no setor bancário. In M. E. A. Lima, J. N. G. de Araujo \& F. de P. Lima (Orgs.), A LER: dimensões ergonômicas e psicossociais. Belo Horizonte: Health.

Lin, T. Y., Teixeira, M. J. \& Barboza, H. F. G. (1998). LER - Lesões por esforços repetitivos (distúrbio ósteomuscular relacionado ao trabalho "DORT"). In Anais do II Simpósio Multidisciplinar de Lesões por Esforços Repetitivos (DORT). São Paulo: Hospital das Clínicas da Faculdade de Medicina da Universidade de São Paulo. 
Murofuse, N.T. \& Marziale, M. H.P. (2001). Mudanças no trabalho e na vida de bancários portadores de lesões por esforços repetitivos: LER. Revista Latino-Americana de Enfermagem, 9 (4), 19-25.

Ribeiro, H. P. (1997). A violência do trabalho no capitalismo: o caso das lesões dos membros superiores por esforços repetitivos em trabalhadores bancários. Tese de Doutorado, Faculdade de Saúde Pública, Universidade de São Paulo, São Paulo.

Ribeiro, H. P. (1999). A violência oculta do trabalho: as lesões por esforços repetitivos. Rio de Janeiro: Fiocruz.

Ribeiro, H. P. (2002). Estado do conhecimento das Lesões por Esforços Repetitivos/LER: atualização e perspectivas. Texto disponível na Internet: www.ergonet.com.br/download/estado-herval.pdf [28 agosto 2008].

Sato, L. (2001). Objeto e pretexto para a construção do campo trabalho e saúde. Cadernos de Saúde Pública, 17 (1), $147-152$.

Segnini, L. R. P. (1995). O trabalho da mulher nos bancos: análise das mudanças tecnológicas e nas relações de trabalho e suas implicações nas qualificações requeridas. Tese de Livre Docência, Faculdade de Educação, Universidade de Campinas, Campinas.

Silva, L. S., Pinheiro, T. M. M. \& Sakurai, E. (2007). Reestruturação produtiva, impactos na saúde e sofrimento mental: o caso de um banco estatal em Minas Gerais, Brasil. Cadernos de Saúde Pública, 23 (12), 2949. 2958.

Verthein, M. A. R. (2001). Jogos de poder instituindo saber sobre as Lesões por Esforços Repetitivos: as redes discursivas da recusa do nexo. Tese de Doutorado, Centro de Estudos da Saúde do Trabalhador e Ecologia Humana, Fundação Oswaldo Cruz, Escola Nacional de Saúde Pública, Rio de Janeiro.

\section{Endereço para correspondência}

debora.couto@terra.com.br,vnavarro@usp.br

Recebido em: 02/09/2008

Aprovado em: 29/03/2009 